JOURNAL OF

SYNCHROTRON

RADIATION

ISSN 1600-5775

Received 8 July 2020

Accepted 7 October 2020

Edited by A. Momose, Tohoku University, Japan

Keywords: multilayers; GIXR; GIEXAFS; soft X-rays; water window.

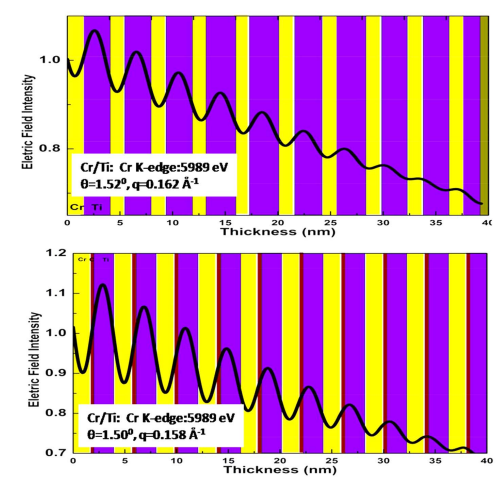

C 2021 International Union of Crystallography

\section{Interface modification of $\mathrm{Cr} / \mathrm{Ti}$ multilayers with $\mathrm{C}$ barrier layer for enhanced reflectivity in the water window regime}

\author{
P. Sarkar, ${ }^{\text {a,b }}$ A. Biswas, ${ }^{\text {a N. Abharana, }}{ }^{\text {a }}$ S. Rai, ${ }^{c}$ M. H. Modic and D. Bhattacharyya ${ }^{\mathrm{a} *}$ \\ ${ }^{\mathbf{a}}$ Atomic and Molecular Physics Division, Bhabha Atomic Research Centre, Mumbai 400085, India, ${ }^{\mathbf{b}} \mathrm{Homi}$ Bhabha \\ National Institute, Mumbai 400094, India, and ${ }^{\mathbf{c} S y n c h r o t r o n ~ U t i l i s a t i o n ~ S e c t i o n, ~ R a j a ~ R a m n n a ~ C e n t r e ~ f o r ~ A d v a n c e d ~}$ \\ Technology, Indore 752013, India. *Correspondence e-mail: dibyendu@barc.gov.in
}

The influence of a carbon barrier layer to improve the reflectivity of $\mathrm{Cr} / \mathrm{Ti}$ multilayers, intended to be used in the water window wavelength regime, is investigated. Specular grazing-incidence X-ray reflectivity results of $\mathrm{Cr} / \mathrm{Ti}$ multilayers with 10 bilayers show that interface widths are reduced to $\sim 0.24 \mathrm{~nm}$ upon introduction of a $\sim 0.3 \mathrm{~nm} \mathrm{C}$ barrier layer at each Cr-on-Ti interface. As the number of bilayers increases to 75 , a multilayer with $\mathrm{C}$ barrier layers maintains almost the same interface widths with no cumulative increase in interface imperfections. Using such interface-engineered $\mathrm{Cr} / \mathrm{C} / \mathrm{Ti}$ multilayers, a remarkably high soft $\mathrm{X}$-ray reflectivity of $\sim 31.6 \%$ is achieved at a wavelength of $2.77 \mathrm{~nm}$ and at a grazing angle of incidence of $16.2^{\circ}$, which is the highest reflectivity reported so far in the literature in this wavelength regime. Further investigation of the multilayers by diffused grazing-incidence X-ray reflectivity and grazing-incidence extended X-ray absorption fine-structure measurements using synchrotron radiation suggests that the improvement in interface microstructure can be attributed to significant suppression of inter-diffusion at $\mathrm{Cr} / \mathrm{Ti}$ interfaces by the introduction of $\mathrm{C}$ barrier layers and also due to the smoothing effect of the $\mathrm{C}$ layer promoting two-dimensional growth of the multilayer.

\section{Introduction}

A high-reflective multilayer mirror is a vital component for extreme ultraviolet and soft X-ray based instrumentation used in lithography and microscopy, X-ray lasers, plasma physics, and astrophysics, synchrotron radiation polarimetry etc., and during the last decade this field has experienced significant growth (Kopylets et al., 2019; Qi et al., 2019; Pradhan et al., 2018; Huang et al., 2016, 2017a,b; Panini et al., 2017; Peng et al., 2016; Li et al., 2013; Fernández-Perea et al., 2013; Yi et al., 2017; Harrison et al., 2013). In particular, the development of high-reflective normal-incidence multilayer (ML) optics for the water window region $(\lambda \simeq 2.3-4.4 \mathrm{~nm})$, where water is transmissive but carbon-based organic materials show strong absorption, has acquired great interest. The main challenge in the fabrication of 'water-window' multilayers is the deposition of hundreds of nanometres to sub-nanometre thin layers, maintaining interface roughness and interlayer mixing to very low values. As a result, the highest reflectance achieved in these MLs in the water window regime is much lower than the theoretical limit. Based on their absorption edges, Sc, Ti and V are the available options as spacer material in combination with absorber materials such as $\mathrm{Cr}, \mathrm{W}, \mathrm{Co}$, Ni having large electron density contrast for developing multilayer mirrors in this region. Among these, $\mathrm{Cr} / \mathrm{Sc}$ multilayers have been the 
most widely studied working above the Sc $L$-edge (Eriksson $e t$ al., 2003, 2008) and the highest reflectance achieved is around $32 \%$ at $3.11 \mathrm{~nm}$ at near-normal incidence (Eriksson et al., 2003). However, not many reports are available for the Ti $L$ edge $(\lambda=2.77 \mathrm{~nm})$, which is important in microscopy applications due to the availability of nitrogen-based table-top plasma sources. Although $\mathrm{Co} / \mathrm{Ti}$ possesses highest reflectivity according to theoretical calculations, experimentally it fails to produce good results due to poor interface morphology (Sarkar et al., 2017, 2020a). Cr, on the other hand, has slightly less electron density contrast with $\mathrm{Ti}$ compared with $\mathrm{Ni}$ or $\mathrm{Co}$, but also has less absorption, thereby allowing a higher number of bilayers in the ML to achieve higher reflectivity. To date, however, the highest normal-incidence reflectance reported for a $\mathrm{Cr} / \mathrm{Ti} \mathrm{ML}$ is only $2.1 \%$ (Ghafoor et al., 2006). Here we report our work on $\mathrm{Cr} / \mathrm{Ti}$ multilayers with a $\mathrm{C}$ barrier layer (BL), fabricated by ion beam deposition method, the purpose of the BL being to reduce imperfections at the $\mathrm{Cr} / \mathrm{Ti}$ interfaces. $\mathrm{C}$ is chosen as the BL because of its lower surface energy $(\gamma)$ of $70-80 \mathrm{~mJ} \mathrm{~m}^{-2}$ (Kumar et al., 2017) compared with both Ti (1.98-2.1 $\mathrm{J} \mathrm{m}^{-2}$ ) and $\mathrm{Cr}\left(2.3 \mathrm{~J} \mathrm{~m}^{-2}\right.$ ) (Vitos et al., 1998; Zebda et al., 2008). According to the growth model proposed by Forgerini \& Marchiori (2014), wetting or de-wetting of a material onto another material depends on the difference in their $\gamma$ value, wetting (de-wetting) of a material with a lower (higher) $\gamma$ being more likely to take place when deposited on a material with higher (lower) $\gamma$. Hence, $\mathrm{C}$ is expected to form a smoother layer on both $\mathrm{Cr}$ and $\mathrm{Ti}$ layers and would thus lead to better interfaces. We have calculated the soft X-ray reflectivity of 75 bi-layer $\mathrm{Cr} / \mathrm{Ti}$ multilayers with $3.8 \mathrm{~nm}$ bi-layer thickness and with different thickness of $\mathrm{C}$ diffusion barrier layer and the reflectivity of the multilayer is found to decrease if the barrier layer thickness is increased beyond $0.3 \mathrm{~nm}$ due to reduction of the refractive index contrast between the absorber and spacer layers. For thicknesses less than $0.3 \mathrm{~nm}$ there is the possibility of formation of a discontinuous barrier layer. Thus, considering these two aspects we had decided on a BL thickness of $0.3 \mathrm{~nm}$. Multilayers with and without $\mathrm{BL}$ have been characterized using specular and diffused hard $\mathrm{X}$-ray grazing-incidence reflectivity (GIXR) measurements, element-specific grazing-incidence extended X-ray absorption fine-structure (GIEXAFS) measurement at the $\mathrm{Cr} K$-edge and finally by soft $X$-ray reflectivity measurements at a wavelength of $2.77 \mathrm{~nm}$. A very significant increase in the soft X-ray reflectivity of the samples has been obtained by applying the $\mathrm{C}$ barrier layers at the interfaces.

\section{Experimental section}

\subsection{Sample preparation}

All ML samples discussed in this work have been deposited by ion beam sputtering (IBS) technique in a state-of-the-art dual ion beam sputtering (DIBS) system (IONSYS-800, Meyer Burger, Germany). All the films have been deposited on $30 \mathrm{~mm} \times 20 \mathrm{~mm}$ crystalline $\mathrm{Si}$ (111) substrates having surface roughness of $\sim 0.2 \mathrm{~nm}$. Prior to depositions the system is evacuated up to $4 \times 10^{-7}$ mbar pressure and, subsequently, using a microwave generator operating at $300 \mathrm{~W}$, argon plasma is generated at $1.4 \times 10^{-4} \mathrm{mbar}$ pressure. The $\mathrm{Cr} / \mathrm{Ti}$ multilayer is designed with bi-layer spacing of $d \simeq 3.8 \mathrm{~nm}$ and nominal thicknesses of $1.5 \mathrm{~nm}$ and $2.3 \mathrm{~nm}$ for the $\mathrm{Cr}$ and $\mathrm{Ti}$ layers, respectively, to achieve a bi-layer to $\mathrm{Cr}$ layer thickness ratio $\left(\Gamma=d_{\mathrm{Cr}} / d\right)$ of 0.4 which we had optimized from our earlier studies (Sarkar et al., 2020b) to obtain the best reflectivity. Four multilayer samples with 10 bilayers were first deposited: (i) with no $\mathrm{C} \mathrm{BL}$, with $0.3 \mathrm{~nm} \mathrm{C} \mathrm{BL}$ at one of the interfaces, (ii) Ti-on-Cr or (iii) Cr-on-Ti, and (iv) with $0.3 \mathrm{~nm} \mathrm{C}$ BL at both interfaces, to study the effect of the BLs. A precalibrated quartz crystal monitor has been used for in situ control of the rate of deposition and thickness of the $\mathrm{Cr}$ and $\mathrm{Ti}$ layers. The other process parameters used in the deposition of the above samples have been kept the same as obtained by optimizing depositions of single-layer $\mathrm{Cr}$ and $\mathrm{Ti}$ films with bulk-like density and very low roughness. For the deposition of a $0.3 \mathrm{~nm} \mathrm{C}$ barrier layer, however, a time-thickness calibration graph was followed, which was generated by depositing a few thicker $\mathrm{C}$ layers and estimating their thickness by ex situ GIXR measurements.

The multilayers were characterized using specular GIXR measurements with a laboratory-based $\mathrm{Cu} K_{\alpha}$ source $(\lambda=$ $0.154 \mathrm{~nm}$ ). GIEXAFS measurements on the $\mathrm{Cr} / \mathrm{Ti}$ multilayer samples have been carried out at the Energy Scanning EXAFS beamline (BL-9) at the Indus-2 synchrotron source $(2.5 \mathrm{GeV}$, $300 \mathrm{~mA}$ ) at the Raja Ramanna Centre for Advanced Technology (RRCAT), Indore, India. Details of the beamline have been reported elsewhere (Basu et al., 2014; Poswal et al., 2014), while the procedure of GIEXAFS measurements has been given in our two earlier communications (Abharana et al., $2019 a, b)$. For the present set of samples, measurements at the $\mathrm{Cr} K$-edge have been carried out in fluorescence mode in the energy range 5900-6400 eV. The soft X-ray reflectivity of the samples at the water window wavelength of $2.77 \mathrm{~nm}$ has been recorded at the BL-03 soft X-ray beamline at the Indus-2 synchrotron source (Modi et al., 2019).

\section{Results and discussions}

\subsection{Specular GIXR measurements}

The inset of Fig. 1 shows the specular GIXR data of the 10 bi-layer samples which clearly shows that after introducing a $0.3 \mathrm{~nm} \mathrm{C}$ barrier layer at the $\mathrm{Cr}-\mathrm{on}-\mathrm{Ti}$ interface (the $\mathrm{Cr} / \mathrm{C} / \mathrm{Ti}$ sample) the Bragg peak reflectivities are definitely enhanced, whereas the Bragg peak reflectivities are reduced for the other two samples, i.e. with the $\mathrm{C}$ barrier layer on the Ti-on-Cr interface (the $\mathrm{Cr} / \mathrm{Ti} / \mathrm{C}$ sample) and with barrier layers at both interfaces (the $\mathrm{Cr} / \mathrm{C} / \mathrm{Ti} / \mathrm{C}$ sample). In order to investigate this aspect further, the specular reflectivities of the 10-bilayer $\mathrm{Cr} /$ $\mathrm{C} / \mathrm{Ti}$ and $\mathrm{Cr} / \mathrm{Ti}$ multilayers samples are fitted with respective theoretical plots generated using the GENX software (Björck \& Andersson, 2007) which works on Parrat's formalism (Parrat, 1954) and are shown in Fig. 1. During fitting to take care of the initial instability of the deposition process and top 
Table 1

Best-fit results of specular, diffused GIXR and soft X-ray reflectivity fitting for $\mathrm{Cr} / \mathrm{Ti}$ multilayer.

\begin{tabular}{lllllllll}
\hline & \multicolumn{3}{l}{ Cr-on-Ti interface } & \multicolumn{3}{c}{ Ti-on-Cr interface } & \multicolumn{2}{c}{$\xi_{\|}(\mathrm{nm})$} \\
\cline { 2 - 8 } Sample & $\sigma(\mathrm{nm})$ & $\sigma_{\mathrm{r}}(\mathrm{nm})$ & $\sigma_{\mathrm{d}}(\mathrm{nm})$ & $\sigma(\mathrm{nm})$ & $\sigma_{\mathrm{r}}(\mathrm{nm})$ & $\sigma_{\mathrm{d}}(\mathrm{nm})$ & $\mathrm{Ti}$ & $\mathrm{Cr}$ \\
\hline$(\mathrm{Cr} / \mathrm{Ti})^{10}$ & 0.43 & & & 0.49 & & & & \\
$(\mathrm{Cr} / \mathrm{C} / \mathrm{Ti})^{10}$ & 0.24 & & & 0.22 & & & & \\
$(\mathrm{Cr} / \mathrm{Ti} / \mathrm{C})^{10}$ & 0.45 & & & 0.55 & & & & \\
$(\mathrm{Cr} / \mathrm{C} / \mathrm{T} / \mathrm{C})^{10}$ & 0.40 & & & 0.56 & & & & \\
$(\mathrm{Cr} / \mathrm{Ti})^{75}$ & 0.55 & 0.13 & 0.53 & 0.40 & 0.22 & 0.34 & 1122.9 & 58.8 \\
$(\mathrm{Cr} / \mathrm{C} / \mathrm{Ti})^{75}$ & 0.29 & 0.21 & 0.10 & 0.21 & 0.11 & 0.18 & 1873.9 & 50.0 \\
$(\mathrm{Cr} / \mathrm{Ti})^{75}(\lambda=2.77 \mathrm{~nm})$ & 0.70 & & & 0.65 & & & & \\
$(\mathrm{Cr} / \mathrm{C} / \mathrm{Ti})^{75}(\lambda=2.77 \mathrm{~nm})$ & 0.31 & & & 0.40 & & & & \\
\hline
\end{tabular}

samples as shown in Fig. 1 and the bestfit parameters have been tabulated in Table 1. However, it can be seen that contrary to the $(\mathrm{Cr} / \mathrm{C} / \mathrm{Ti})^{10}$ sample the $\sigma$ values of these samples have not been decreased after deposition of the $\mathrm{C}$ barrier layer which is also reflected in the reflectivity of these multilayers as shown in the inset of Fig. 1.

Subsequently, two Cr/Ti multilayer samples with 75 bi-layers have been deposited: one without any BL and the other with a $\mathrm{C} \mathrm{BL}$ at each $\mathrm{Cr}$-on-Ti

surface roughness, respectively, separate $\mathrm{Ti}$ and $\mathrm{Cr}$ layers are chosen just above the substrate and on top of the multilayer, respectively. The rest of the ML stack has been modelled by a $\mathrm{Cr} / \mathrm{Ti}$ bi-layer stack repeated nine times with the same thickness for all $\mathrm{Cr}$ layers, all $\mathrm{Ti}$ layers and all $\mathrm{C}$ layers. The $\mathrm{C}$ barrier layer thickness, determined from best fit, lies in the range $\sim 0.28-0.31 \mathrm{~nm}$. The achieved thicknesses of the $\mathrm{Cr}$ and Ti layers are also found to be very close to the nominal values; for example, for the 10 bi-layer $\mathrm{Cr} / \mathrm{Ti} \mathrm{ML}$ sample, the $\mathrm{Cr}$ and Ti layer thicknesses obtained from fitting of GIXR data are $1.47 \mathrm{~nm}$ and $2.35 \mathrm{~nm}$, respectively, which agree very well with their nominal values. The interface imperfections are taken care of by an interface width $(\sigma)$ [comprising both interface roughness $\left(\sigma_{\mathrm{r}}\right)$ and diffusion $\left.\left(\sigma_{\mathrm{d}}\right)\right]$ at each interface with different average values for $\mathrm{Cr}$-on- $\mathrm{Ti}$ and Ti-on-Cr interfaces. The best-fit results are given in Table 1, showing that, after introducing $\mathrm{C}$ barrier layers at the $\mathrm{Cr}$-on-Ti interfaces, the interface width $\sigma$ reduces significantly from $0.43 \mathrm{~nm}$ to $0.24 \mathrm{~nm}$ for the Cr-on-Ti interface. Reduction in $\sigma$ due to application of the $\mathrm{C} \mathrm{BL}$ may be either due to less interdiffusion or low interface roughness, or both. It should be mentioned here that we have also carried out theoretical fitting of the GIXR data of the $(\mathrm{Cr} / \mathrm{Ti} / \mathrm{C})^{10}$ or $(\mathrm{Cr} / \mathrm{C} / \mathrm{Ti} / \mathrm{C})^{10}$

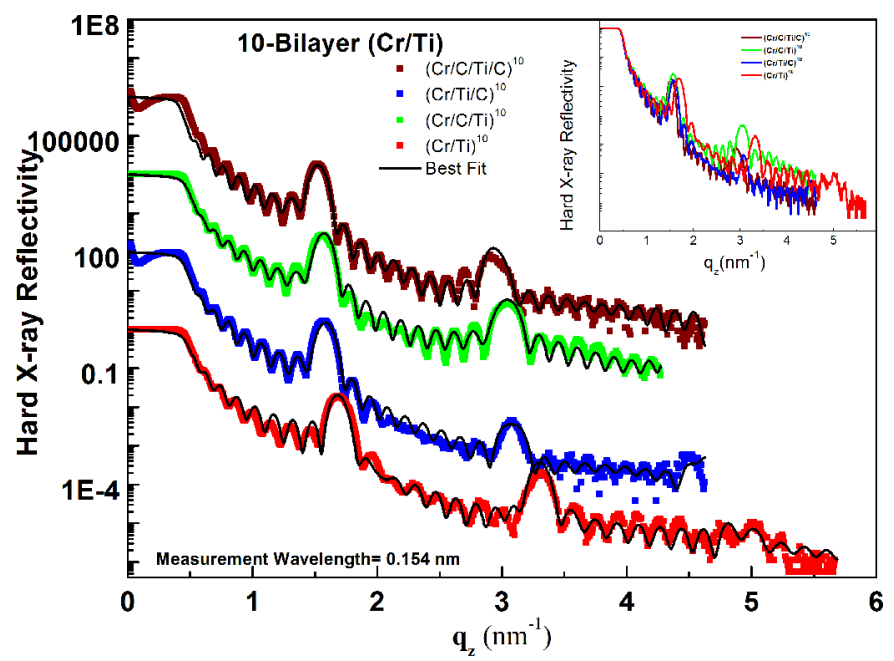

Figure 1

Specular GIXR data with best-fit theoretical simulation of $\mathrm{Cr} / \mathrm{Ti}, \mathrm{Cr} / \mathrm{Ti} / \mathrm{C}$, $\mathrm{Cr} / \mathrm{C} / \mathrm{Ti}$ and $\mathrm{Cr} / \mathrm{C} / \mathrm{Ti} / \mathrm{C} 10$ bi-layer ML samples. Inset: specular GIXR data of $\mathrm{Cr} / \mathrm{Ti}, \mathrm{Cr} / \mathrm{Ti} / \mathrm{C}, \mathrm{Cr} / \mathrm{C} / \mathrm{Ti}$ and $\mathrm{Cr} / \mathrm{C} / \mathrm{Ti} / \mathrm{C} 10$ bi-layer ML samples. interface. The $\mathrm{Cr}$ and $\mathrm{Ti}$ layer thicknesses were decreased equally in the latter sample compared with the former one in order to maintain the same $d$-spacing of $3.8 \mathrm{~nm}$. Fig. 2 shows the specular GIXR data of both the 75-bilayer $\mathrm{Cr} / \mathrm{Ti}$ multilayer samples without and with $\mathrm{C}$ barrier at each $\mathrm{Cr}$-on-Ti interface along with respective best-fit theoretical simulations; the best-fit results are also shown in Table 1. Two important observations can be made from the results: first for the $\mathrm{Cr} / \mathrm{Ti}$ ML without BL the interface width $\sigma$ at the $\mathrm{Cr}$-on-Ti interface increases sharply as more layers are being added; this implies that there is a slow accumulation of interface roughness as more layers are being deposited. However, the 75 bi-layer $\mathrm{Cr} / \mathrm{C} / \mathrm{Ti} \mathrm{ML}$ maintains almost the same small interface width as in the 10 bi-layer sample. Thus, introduction of a C BL helps to stop the cumulative increase in interface imperfections across the depth of the multilayers. Thus the sample follows the mechanism of 'restart of growth' model which proposes that the growth of the thin film restarts at every interface (Savage et al., 1992). Secondly, introduction of a C barrier layer not only reduces the interface width for the $\mathrm{Cr}$-on- $\mathrm{Ti}$ interface but also improves the other (Ti-on-Cr) interface significantly. In the absence of a C BL, Cr significantly diffuses into $\mathrm{Ti}$ and also $\mathrm{Cr}$ adatoms follow island-type growth on $\mathrm{Ti}$

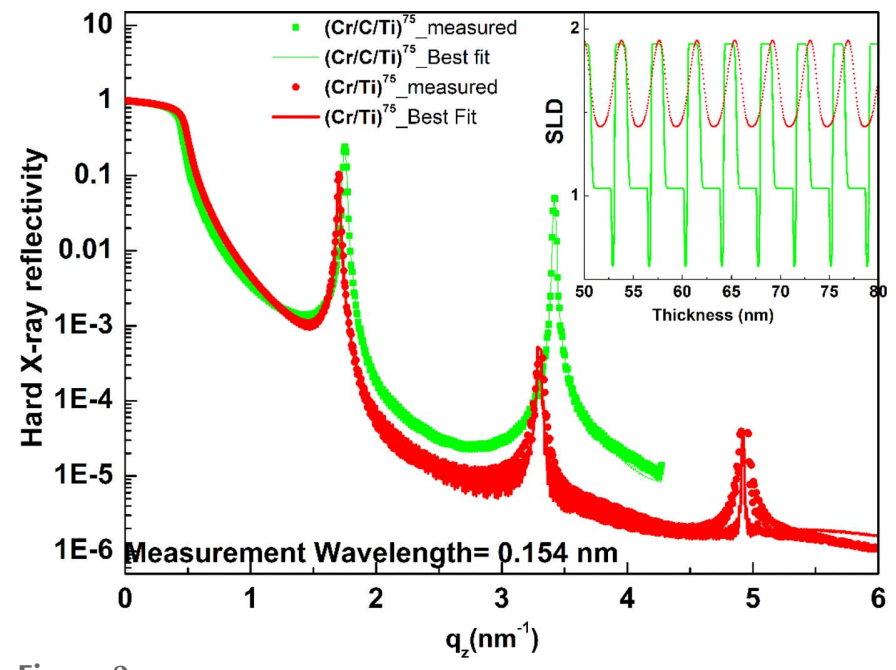

Figure 2

Specular GIXR data with best-fit theoretical simulation of $\mathrm{Cr} / \mathrm{Ti}$ and $\mathrm{Cr} /$ $\mathrm{C} / \mathrm{Ti} 75$ bi-layer ML samples. Inset: scattering length density (SLD) plots of the samples obtained from best-fit results of specular reflectivity data. 
due to non-wetting conditions of surface energy $(\gamma)$, which contributes towards the large interface width. Although the Ti layer always wets the underlying $\mathrm{Cr}$ layer, it follows its morphology of the $\mathrm{Cr}$ layer beneath it. Thus when the $\mathrm{Cr}$ layer itself does not follow two-dimensional growth, it adversely affects the quality of the Ti-on-Cr interface. However, when the $\mathrm{C}$ barrier layer is introduced on the Ti layer, it creates a smoothening effect promoting a perfect two-dimensional growth of $\mathrm{Cr}$ with very low interface imperfections. The $\mathrm{Ti}$ layer in turn grows on a smooth two-dimensional Cr surface, and hence results in a sharp and parallel growth, which is reflected in the lower interface width for the Ti-on-Cr interface. Thus a C BL significantly improves the interface imperfections of the $\mathrm{Cr} / \mathrm{Ti}$ MLs by introducing a smoothening effect at the interfaces.

The above speculation is further supported by the scattering length density (SLD) variation of the multilayers. SLD is a measure of the scattering power of a material which increases with the physical density contrast as well as the intrinsic scattering power of the 'scattering entities' (http://gisaxs. com/index.php/Scattering_Length_Density). If the consecutive layers show high electron density contrast, then a SLD change will be sharp, whereas, if there is an overlapping of consecutive layers into each other leading to low electron density contrast, the SLD change will be gradual and smooth. The SLD variations for the MLs, as extracted from the GIXR data of the samples, are plotted in the inset of Fig. 2. It is clearly depicted that for the $\mathrm{Cr} / \mathrm{Ti} \mathrm{ML}$, the contrast between $\mathrm{Cr}$ and $\mathrm{Ti}$ becomes really poor resulting from an increased $\mathrm{Ti}$ density, which is being attributed towards enhanced overlapping between the $\mathrm{Ti}$ and $\mathrm{Cr}$ layers. However, for a sample with C BLs, SLD values are close to theoretical values and SLD variations at the interfaces are sharp with large density contrast. The SLD variation thus qualitatively demonstrates that density contrast between $\mathrm{Cr}$ and Ti increases sharply with the addition of a $\mathrm{C}$ barrier layer indicating less overlapping at the interfaces of this sample which can be due to less diffusion of $\mathrm{Cr}$ into $\mathrm{Ti}$ or due to flat interfaces with low interface roughness or due to both.

\subsection{Diffused GIXR measurements}

Thus, specular GIXR results undoubtedly establish that a C BL causes significant reduction of interface imperfections in $\mathrm{Cr} / \mathrm{Ti}$ MLs. However, no distinction between graded (interdiffused) and truly rough interfaces can be made only by specular X-ray reflectivity measurement, i.e. we cannot decouple $\sigma_{\mathrm{r}}$ and $\sigma_{\mathrm{d}}$ in $\sigma$. Thus for complete characterization of the imperfections at both Cr-on-Ti and Ti-on-Cr interfaces, both the samples have subsequently been characterized using $\mathrm{X}$-ray reflectivity in non-specular or diffused mode in rocking scan geometry since interface roughness gives rise to significant diffused reflectivity from the samples. The details of the measurements and data analysis procedure have been given in our previous communications (Sarkar et al., 2017; Biswas \& Bhattacharyya, 2011). The measured diffused GIXR profiles of the samples are plotted in Fig. 3; a qualitative comparison of both graphs shows that the area under the curve reduces with the introduction of the $\mathrm{C}$ barrier layer. This implies that some of the intensity that was previously scattered in diffused directions is now being reflected in the specular direction, clearly indicating a change in interface morphology. For further analysis, the peak profiles of the diffused data have been fitted with theoretically simulated plots of the whole multilayer structures, computed by the first-order distorted wave Born approximation (Windt et al., 2000; Holý \& Baumbach, 1994; de Boer, 1996). The best-fit theoretical plots are shown in Fig. 3 along with the experimental data, while the best-fit values for $\sigma_{\mathrm{r}}, \sigma_{\mathrm{d}}$ and in-plane correlation length $\left(\xi_{\Pi}\right)$ are listed in Table 1 . It is seen from Table 1 that a $\mathrm{C} \mathrm{BL}$ reduces interface diffusion $\left(\sigma_{\mathrm{d}}\right)$ drastically on the Cr-on-Ti interface, manifesting the fact that for such $\mathrm{Cr} / \mathrm{Ti}$ multilayers inter-diffusion plays a dominant role in determining the performance of the multilayers and introduction of the $\mathrm{C} \mathrm{BL}$ helps to suppress the inter-diffusion significantly and improves the contrast between two materials. It can also be seen from Table 1 that for Ti-on-Cr interfaces both $\sigma_{\mathrm{r}}$ and $\sigma_{\mathrm{d}}$ reduce for the $\mathrm{Cr} / \mathrm{C} / \mathrm{Ti}$ sample. It is in corroboration with the fact that the Ti layer always wets the underlying $\mathrm{Cr}$ layer and follows its morphology. As the Cr layer itself follows a smoother growth with introduction of the $\mathrm{C} \mathrm{BL}$, it directly helps to improve the smoothness of the Ti layer and the Ti-on-Cr interface as well. The above result corroborates with that obtained by specular reflectivity and also justifies the fact that, with introduction of the $\mathrm{C} \mathrm{BL}$, the in-plane correlation length $\left(\xi_{\Pi}\right)$, which is closely associated with the atomic arrangements and morphology, increases significantly for the Ti layers. It should be mentioned here that, considering the errors in measurements and the fitting process, the overall uncertainties in the estimated parameters from specular and diffused GIXR measurements are found to be less than 5\% (Biswas \& Bhattacharyya, 2011) since these measurements are carried out with a hard X-ray probe of very low wavelength $(\sim 1 \AA)$.

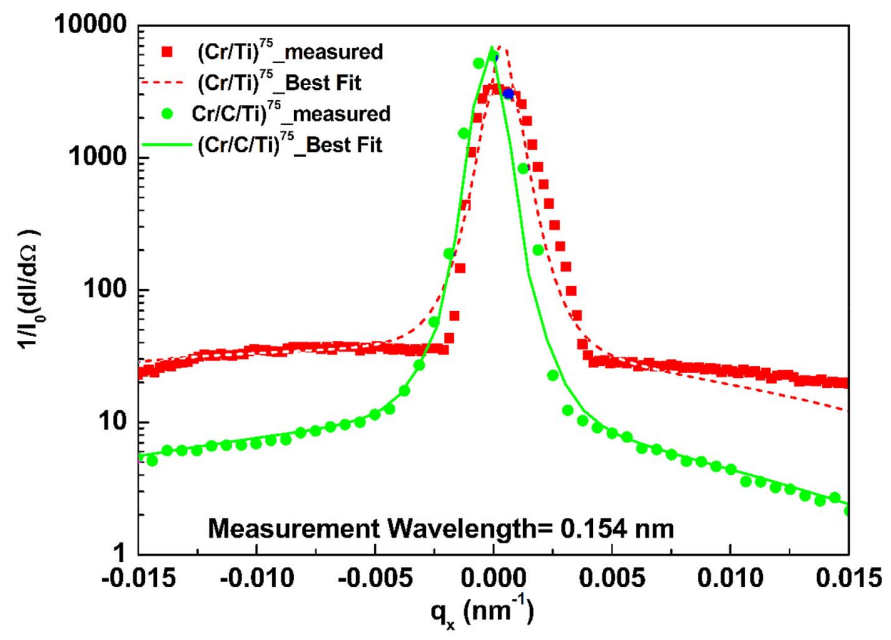

Figure 3

Diffused GIXR data with best-fit theoretical simulation of $\mathrm{Cr} / \mathrm{Ti}$ and $\mathrm{Cr} / \mathrm{C} / \mathrm{Ti} 75$ bi-layer ML samples. 


\subsection{GIEXAFS measurements}

For further insight into the diffusion of $\mathrm{Cr}$ atoms in Ti layers and its reduction due to introduction of the C BL, a depthselective study of both the multilayers has been carried out by GIEXAFS measurements using synchrotron radiation. The GIEXAFS technique relies on the fact that a standing wave pattern is generated within a multilayer due to the interference between the incident wave and waves reflected from the multilayer interfaces when X-rays are incident on a multilayer structure at a grazing angle of incidence higher than the critical angle (Meyer et al., 2000; Gupta et al., 2007; Heald, 1992). Positions of the nodes and antinodes of the standing wave inside the multilayer can be precisely controlled by changing the grazing angle of incidence. A GIEXAFS measurement is generally carried out at a particular angle of incidence of the synchrotron beam with respect to the sample surface, which ensures positioning of the antinodes at a particular position throughout the multilayer. Since maximum electric field at the antinode regions ensures maximum absorption of X-rays in those regions and hence maximum fluorescence EXAFS signal, EXAFS measurement at that particular grazing angle of incidence yields average information preferentially from those regions only. We have fruitfully utilized the GIEXAFS technique in the non-destructive depth-dependent characterizing of $\mathrm{Mo} / \mathrm{Si}$ and $\mathrm{Ni} / \mathrm{Ti}$ multilayer structures earlier (Abharana et al., 2019a,b).

The IMD computer code (Windt, 2000) which also works on Parrat's formalism (Parrat, 1954) has been used to theoretically generate the electric field intensity distribution of the $\mathrm{X}$-ray standing wave inside the 10 bi-layer $\mathrm{Cr} / \mathrm{Ti} \mathrm{ML}$ and $\mathrm{Cr} / \mathrm{C} / \mathrm{Ti} \mathrm{ML}$ structures at different grazing angles of incidence for $\mathrm{Cr} K$-edge energy of $5989 \mathrm{eV}$ where $\mathrm{Cr}$, Ti and $\mathrm{C}$ layer thicknesses as obtained from fitting of specular GIXR data of the respective samples have been used. Here we are interested in investigating the diffusion of $\mathrm{Cr}$ inside the Ti layers. It can be seen from Fig. 4 that, for a measurement at a grazing angle of incidence of $1.52^{\circ}, \mathrm{Cr}$ atoms inside the Ti layers can be probed for the $\mathrm{Cr} / \mathrm{Ti}$ ML since the antinodes are situated at $\mathrm{Ti}$ bulk layers in this case, the corresponding angle being $1.50^{\circ}$ for the $\mathrm{Cr} / \mathrm{C} / \mathrm{Ti} \mathrm{ML}$. It should be mentioned here that the above values are calculated for the $\mathrm{Cr} K$-edge energy of $5989 \mathrm{eV}$, and, when the energy of the incident X-ray photon is varied during an EXAFS measurement, standing wave positions in the ML also change. To prohibit this, the measurements are made at constant $q$ mode where the grazing angle of incidence of the X-rays on the sample is also changed in a pre-calculated manner $(q=4 \pi \sin \theta / \lambda)$ by adding a computer code in the beamline control software such that the $q$ value always remains fixed and thus the standing wave antinode positions remain unaltered all over the energy band during a particular EXAFS scan (Heald, 1992).

The inset of Fig. 5 shows the $\mathrm{Cr} K$-edge EXAFS $[\mu(E)$ versus $E]$ spectra of the $\mathrm{Cr} / \mathrm{Ti}$ and $\mathrm{Cr} / \mathrm{C} / \mathrm{Ti}$ multilayers measured at a constant $q$ value of $0.162 \AA^{-1}$ and $0.158 \AA^{-1}$, respectively, to probe the local structure of $\mathrm{Cr}$ inside the $\mathrm{Ti}$ layers. The EXAFS data have been analysed following the
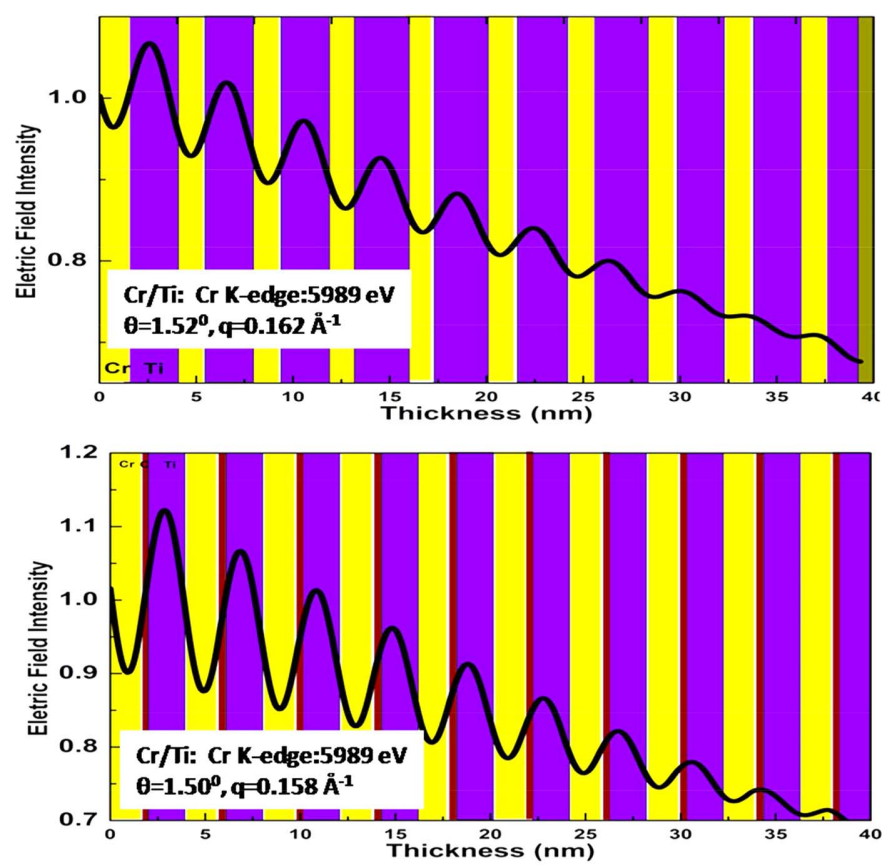

Figure 4

Electric field intensity distribution of X-ray standing wave inside 10 bilayer ML samples Cr/Ti ML (top) and $\mathrm{Cr} / \mathrm{C} / \mathrm{Ti}$ ML (bottom).

standard procedure (Koningsberger, 1988) where the $\mu(E)$ versus $E$ data are first converted to $\chi(E)$ versus $E$ data where

$$
\chi(E)=\frac{\mu(E)-\mu_{0}(E)}{\Delta \mu_{0}\left(E_{0}\right)},
$$

where $E_{0}$ is the absorption edge energy, $\mu_{0}(E)$ is the bare atom background and $\Delta \mu_{0}\left(E_{0}\right)$ is the step in the $\mu(E)$ value at the absorption edge. Subsequently, the $\chi(E)$ versus $E$ data have been converted to $\chi(k)$ versus $k$, where photoelectron wavenumber $(k)$ is defined as

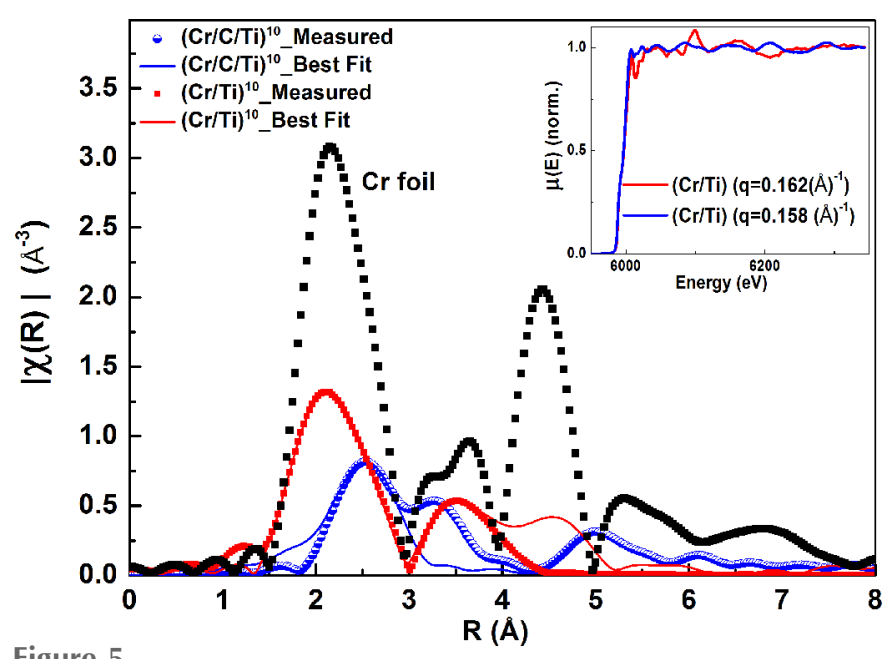

Figure 5

$\chi(R)$ versus $R$ plots surrounding $\mathrm{Cr}$ atoms inside Ti layers for the $10 \mathrm{bi}-$ layer $\mathrm{Cr} / \mathrm{Ti}$ and $\mathrm{Cr} / \mathrm{C} / \mathrm{Ti} \mathrm{ML}$ samples along with that of $\mathrm{Cr}$ foil. Inset: EXAFS $[\mu(E)$ versus $E]$ spectra of the two samples. 


$$
k=\left[\frac{2 m\left(E-E_{0}\right)}{\hbar^{2}}\right]^{1 / 2} .
$$

Finally the $\chi(k)$ versus $k$ data are Fourier transformed to derive the $\chi(R)$ versus $R$ plots. The above reduction and Fourier transform of the data have been carried out using the ATHENA subroutine available within the IFEFFIT software package (Ravel \& Newville, 2005).

Fig. 5 shows the Fourier-transformed EXAFS (FT-EXAFS) data or $\chi(R)$ versus $R$ plots of the $\mathrm{Cr} / \mathrm{Ti}$ and $\mathrm{Cr} / \mathrm{C} / \mathrm{Ti}$ multilayers which probe the local structure of $\mathrm{Cr}$ within the $\mathrm{Ti}$ layers. It should be mentioned here that the peak positions in the $R$ space differ from the actual bond length values by a phase factor, which generally amounts to an increase of $\sim 0.3-$ $0.5 \AA$ from the peak position values, depending on the type of the nearest neighbour scatterer. It can be seen from Fig. 5 that for the $\mathrm{Cr} / \mathrm{Ti}$ sample the major first shell $\mathrm{Cr}$ peak resembles that of $\mathrm{Cr}$ foil both in terms of peak position (which depicts the $\mathrm{Cr}-\mathrm{Cr}$ bond length) and peak intensity (which signifies the number of atoms in the coordination shell) indicating that the $\mathrm{Cr}$ local structure inside the Ti layer is similar to bulk $\mathrm{Cr}$, manifesting significant diffusion of $\mathrm{Cr}$ atoms inside the $\mathrm{Ti}$ layers. In the case of the $\mathrm{Cr} / \mathrm{C} / \mathrm{Ti}$ sample, however, the first major $\mathrm{Cr}$ peak is significantly reduced in intensity and is also shifted to higher $R$ value indicating that the local structure of $\mathrm{Cr}$ is distorted inside the Ti layers indicating that unit shells of the $\mathrm{Cr}$ body-centred cubic structure cannot be formed in this case manifesting that the $\mathrm{C}$ BL helps to reduce $\mathrm{Cr}$ diffusion into Ti. Thus the above GIEXAFS results unambiguously show that the use of a $\mathrm{C} B L$ reduces diffusion of $\mathrm{Cr}$ inside the Ti layers considerably which corroborates with our findings from the specular and diffused GIXR results discussed above.

\subsection{Soft X-ray reflectivity measurements}

Finally, soft X-ray reflectivities ( $90 \%$ s-polarization) of the $\mathrm{Cr} / \mathrm{Ti}$ and $\mathrm{Cr} / \mathrm{C} / \mathrm{Ti}$ multilayer samples with 75 bi-layers were measured at the BL-03 soft X-ray beamline at the Indus-2 synchrotron radiation source at a wavelength of $2.77 \mathrm{~nm}$ or energy of $447.6 \mathrm{eV}$ which is just below the Ti $L_{3}$-edge energy (Modi et al., 2019). As can be seen from Fig. 6, for the $\mathrm{Cr} / \mathrm{Ti}$ sample with 75 bi-layers, $\sim 3.1 \%$ peak reflectivity has been obtained at a $21.4^{\circ}$ grazing angle of incidence, while for the $\mathrm{Cr} / \mathrm{C} / \mathrm{Ti}$ ML having 75 bi-layers the reflectivity value is significantly enhanced to $\sim 16.23 \%$ at approximately the same grazing angle of incidence and measurement wavelength. The soft X-ray reflectivity data have also been fitted with theoretically simulated plots assuming the sample structure obtained from the best fit of hard X-ray GIXR data, varying only the interface width $\sigma$ values. The best-fit theoretical simulations are also shown in Fig. 6 and the best-fit $\sigma$ values are shown in Table 1. It can be seen that the trend of the $\sigma$ values obtained from hard X-ray and soft X-ray data are similar for the multilayers with and without $\mathrm{C}$ barrier layer; however, the values obtained from soft $\mathrm{X}$-ray data are higher. We have observed this in our earlier work on $\mathrm{Co} / \mathrm{Ti}$ multilayer samples also (Sarkar et al., 2017), which implies that interface imperfections affect the soft X-ray reflectivity more than the hard

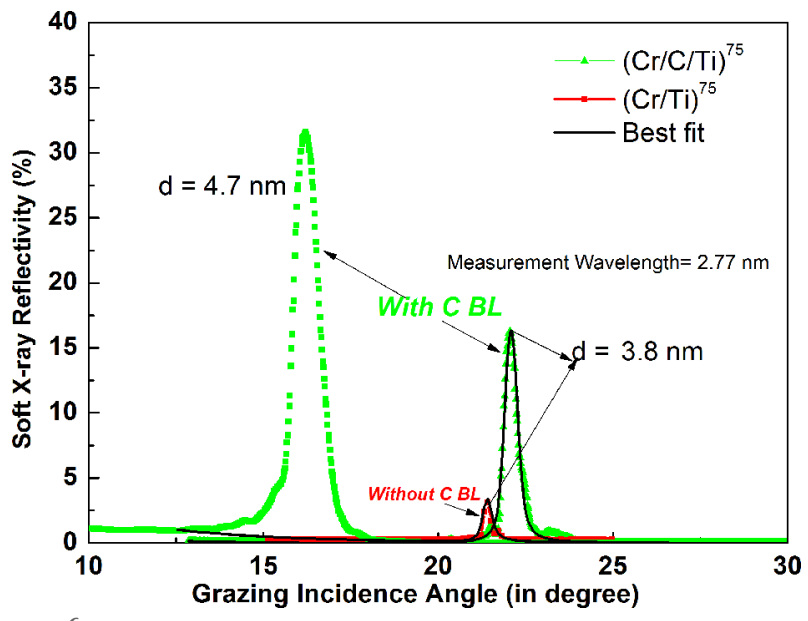

Figure 6

Soft X-ray reflectivity data along with best-fit theoretical simulations of 75 bi-layer $\mathrm{Cr} / \mathrm{Ti}$ and $\mathrm{Cr} / \mathrm{C} / \mathrm{Ti} \mathrm{ML}$ samples measured at a $2.77 \mathrm{~nm}$ soft $\mathrm{X}$-ray wavelength with synchrotron radiation.

$\mathrm{X}$-ray reflectivity of the samples. Similar observation has also been made by Ghafoor et al. (2006) for $\mathrm{Cr} / \mathrm{Ti}$ multilayer samples, which also shows that in these multilayers the accumulation of low spatial frequency interface imperfections (comparable with soft X-ray wavelength length scale) is higher than that of high spatial frequency imperfections (comparable with hard X-ray wavelength length scale).

It can also be seen from the above figure that, for a $\mathrm{Cr} / \mathrm{C} / \mathrm{Ti}$ multilayer of slightly higher bilayer thickness of $4.7 \mathrm{~nm}$, with a $0.3 \mathrm{~nm} \mathrm{C} \mathrm{BL}$ we have observed very high $(\sim 31.6 \%)$ reflectivity for $16.2^{\circ}$ grazing angle of incidence at the same measurement wavelength, which is the highest reflectivity reported so far in the literature in this wavelength regime. The significant increase in soft X-ray reflectivity of the ML samples with $\mathrm{C} \mathrm{BL}$ is due to the decrease in diffusion of $\mathrm{Cr}$ inside the Ti layers, smoothening effect of the $\mathrm{C}$ layer leading to twodimensional growth and consequent improvement in interface imperfections.

\section{Conclusion}

$\mathrm{Cr} / \mathrm{Ti}$ multilayers have been prepared by ion beam sputtering for possible applications in the water window soft X-ray regime. It has been observed from specular GIXR measurements that, when a very thin ( $\sim 0.3 \mathrm{~nm}$ thick $) \mathrm{C}$ barrier layer is deposited at each Cr-on-Ti interface, interface imperfections of the ML decreases sharply. It has also been observed that for this $\mathrm{Cr} / \mathrm{C} / \mathrm{Ti} \mathrm{ML}$, as the number of bi-layers is increased from 10 to 75 , there is almost no cumulative accumulation of interface imperfections implying that the multilayer follows the 'restart of growth' model which proposes that the growth of the thin film restarts at every interface. The variation of scattering length density obtained from GIXR measurements also shows that the density contrast between $\mathrm{Cr}$ and $\mathrm{Ti}$ increases sharply with addition of a $\mathrm{C}$ barrier layer indicating less overlapping between the two layers at the interfaces of this sample. Further investigation by diffused X-ray reflectivity measurements undoubtedly establishes that the $\mathrm{C}$ 
barrier layer reduces interface diffusion drastically on the $\mathrm{Cr}$-on-Ti interface. Moreover, the $\mathrm{C}$ layer having less surface energy wets both $\mathrm{Cr}$ and $\mathrm{Ti}$ layers, thus leading to perfect twodimensional growth of the layers and thus reducing imperfections at both Cr-on-Ti and $\mathrm{Ti}$-on-Cr interfaces and also improving the in-plane or lateral correlation length. It is further confirmed by non-destructive depth-dependent and element-specific measurement by the synchrotron radiation based GIEXAFS technique which also unambiguously shows that use of a $\mathrm{C} B L$ reduces diffusion of $\mathrm{Cr}$ inside the Ti layers considerably. Finally for this interface engineered $\mathrm{Cr} / \mathrm{C} / \mathrm{Ti}$ multilayer, an enhancement of soft X-ray reflectivity by more than five times compared with an equivalent multilayer without $\mathrm{C}$ barrier layer has been found at a water window soft $\mathrm{X}$-ray wavelength of $2.77 \mathrm{~nm}$ and at $21.4^{\circ}$ grazing angle of incidence. Also a remarkably high soft X-ray reflectivity of $\sim 31.6 \%$ is achieved at $16.2^{\circ}$ grazing angle of incidence, such a high reflectivity in the water window wavelength regime being reported for the first time in the literature.

\section{References}

Abharana, N., Biswas, A., Sarkar, P., Rai, S., Singh, S., Kumar, S., Jha, S. N. \& Bhattacharyya, D. (2019a). Vacuum, 169, 108864.

Abharana, N., Biswas, A., Sarkar, P., Rajput, P., Rajnarayan, D., Rao, K. D., Modi, M. H., Bhattacharyya, D., Jha, S. N. \& Sahoo, N. K. (2019b). Thin Solid Films, 673, 126-135.

Basu, S., Nayak, C., Yadav, A. K., Agrawal, A., Poswal, A. K., Bhattacharyya, D., Jha, S. N. \& Sahoo, N. K. (2014). J. Phys. Conf. Ser. 493, 012032.

Biswas, A. \& Bhattacharyya, D. (2011). J. Appl. Phys. 109, 084311. Björck, M. \& Andersson, G. (2007). J. Appl. Cryst. 40, 1174-1178.

Boer, D. K. G. de (1996). Phys. Rev. B, 53, 6048-6064.

Eriksson, F., Ghafoor, N., Hultman, L. \& Birch, J. (2008). J. Appl. Phys. 104, 063516.

Eriksson, F., Johansson, G. A., Hertz, H. M., Gullikson, E. M. U., Kreissig, U. \& Birch, J. (2003). Opt. Lett. 28, 2494-2496.

Fernández-Perea, M., Descalle, M., Soufli, R., Ziock, K. P., Alameda, J., Baker, S. L. T. J., McCarville, T. J., Honkimäki, V., Ziegler, E., Jakobsen, F. E., Christensen, M. J. \& Pivovaroff, M. J. (2013). Phys. Rev. Lett. 111, 027404.

Forgerini, F. L. \& Marchiori, R. (2014). Biomatter, 4, e28871.

Ghafoor, N., Persson, P. O. A., Birch, J., Eriksson, F. \& Schäfers, F. (2006). Appl. Opt. 45, 137-143.

Gupta, A., Rajput, P. \& Meneghini, C. (2007). Phys. Rev. B, 76, 195401.

Harrison, F. A., Craig, W. W., Christensen, F. E., Hailey, C. J., Zhang, W. W., Boggs, S. E., Stern, D., Cook, W. R., Forster, K., Giommi, P., Grefenstette, B. W., Kim, Y., Kitaguchi, T., Koglin, J. E., Madsen, K. K., Mao, P. H., Miyasaka, H., Mori, K., Perri, M., Pivovaroff, M. J., Puccetti, S., Rana, V. R., Westergaard, N. J., Willis, J., Zoglauer, A., An, H., Bachetti, M., Barrière, N. M., Bellm, E. C., Bhalerao, V., Brejnholt, N. F., Fuerst, F., Liebe, C. C., Markwardt, C. B., Nynka, M., Vogel, J. K., Walton, D. J., Wik, D. R., Alexander, D. M., Cominsky, L. R., Hornschemeier, A. E., Hornstrup, A., Kaspi, V. M., Madejski, G. M., Matt, G., Molendi, S., Smith, D. M., Tomsick, J. A., Ajello, M., Ballantyne, D. R., Baloković, M., Barret, D., Bauer, F. E., Blandford, R. D., Brandt, W. N., Brenneman, L. W., Chiang, J., Chakrabarty, D., Chenevez, J., Comastri, A., Dufour, F.,
Elvis, M., Fabian, A. C., Farrah, D., Fryer, C. L., Gotthelf, E. V., Grindlay, J. E., Helfand, D. J., Krivonos, R., Meier, D. L., Miller, J. M., Natalucci, L., Ogle, P., Ofek, E. O., Ptak, A., Reynolds, S. P., Rigby, J. R., Tagliaferri, G., Thorsett, S. E., Treister, E. \& Urry, C. M. (2013). ApJ, 770, 103.

Heald, S. M. (1992). Rev. Sci. Instrum. 63, 873-878.

Holý, V. \& Baumbach, T. (1994). Phys. Rev. B, 49, 10668-10676.

Huang, Q., Fei, J., Liu, Y., Li, P., Wen, M., Xie, C., Jonnard, P., Giglia, A., Zhang, Z., Wang, Z. \& Wang, Z. (2016). Opt. Lett. 41, 701704.

Huang, Q., Medvedev, V. V., van de Kruijs, R., Yakshin, A., Louis, E. \& Bijkerk, F. (2017a). Appl. Phys. Rev. 4, 011104.

Huang, Q., Yi, Q., Cao, Z., Qi, R., Loch, R. A., Jonnard, P., Wu, M., Giglia, A., Li, W., Louis, E., Bijkerk, F., Zhang, Z. \& Wang, Z. (2017b). Sci. Rep. 7, 12929.

Koningsberger, D. C. (1988). X-ray Absorption: Principles, Applications, Techniques of EXAFS, SEXAFS, and XANES. New York: John Wiley and Sons.

Kopylets, I., Devizenko, O., Zubarev, E., Kondratenko, V., Artyukov, I., Vinogradov, A. \& Penkov, O. (2019). J. Nanosci. Nanotechnol. 19, 518-531.

Kumar, M., Javid, A. \& Han, J. G. (2017). Langmuir, 33, 2514-2522.

Li, B., Higashiguchi, T., Otsuka, T., Jiang, W., Endo, A., Dunne, P. \& O'Sullivan, G. (2013). Appl. Phys. Lett. 102, 041117.

Meyer, D. C., Richter, K., Paufler, P., Gawlitza, P. \& Holz, Th. (2000). J. Appl. Phys. 87, 7218-7226.

Modi, M. H., Gupta, R. K., Kane, S. R., Prasad, V., Garg, C. K., Yadav, P., Raghuvanshi, V. K., Singh, A. \& Sinha, M. (2019). AIP Conf. Proc. 2054, 060022.

Panini, S. S., Sreekumar, P., Marshall, H. L., Narendranath, S., Nayak, M. \& Athiray, P. S. (2017). J. Astron. Telesc. Instrum. Syst. 4, 011002.

Parrat, L. G. (1954). Phys. Rev. 95, 359-369.

Peng, J., Li, W., Huang, Q. \& Wang, W. (2016). Sci. Rep. 6, 31522.

Poswal, A. K., Agrawal, A., Yadav, A. K., Nayak, C., Basu, S., Kane, S. R., Garg, C. K., Bhattachryya, D., Jha, S. N. \& Sahoo, N. K. (2014). AIP Conf. Proc. 1591, 649-651.

Pradhan, P. C., Majhi, A. \& Nayak, M. (2018). J. Appl. Phys. 123, 095302.

Qi, R., Huang, Q., Fei, J., Kozhevnikov, I. V., Liu, Y., Li, P., Zhang, Z. \& Wang, Z. (2019). Materials, 12, 2936.

Ravel, B. \& Newville, M. (2005). J. Synchrotron Rad. 12, 537-541.

Sarkar, P., Biswas, A., De, R., Divakar Rao, K., Ghosh, S., Modi, M. H., John, S., Barshilia, H. C., Bhattacharyya, D. \& Sahoo, N. K. (2017). Appl. Opt. 56, 7525.

Sarkar, P., Biswas, A., Ghosh, S. K., Rai, S., Modi, M. H. \& Bhattacharyya, D. (2020a). Thin Solid Films, 693, 137688.

Sarkar, P., Biswas, A., Rai, S., Srivastava, H., Mandal, S., Modi, M. H. \& Bhattacharyya, D. (2020b). Vacuum, 181, 109610.

Savage, D. E., Schimke, N., Phang, Y. H. \& Lagally, M. G. (1992). J. Appl. Phys. 71, 3283-3293.

Vitos, L., Ruban, A. V., Skriver, H. L. \& Kollár, J. (1998). Surf. Sci. 411, $186-202$.

Windt, D. L. (2000). IMD Version 4.1.1, http://cletus.phys.columbia. edu/windt/idl.

Windt, D. L., Christensen, F. E., Craig, W. W., Hailey, C., Harrison, F. A. M., Jimenez-Garate, M., Kalyanaraman, R. \& Mao, P. H. (2000). J. Appl. Phys. 88, 460-470.

Yi, Q., Huang, Q., Zhang, J., Wang, X., Qi, R., Zhang, Z., Xu, R., Peng, T., Jonnard, P., Giglia, A. \& Wang, Z. (2017). Vacuum 146, 187-193.

Zebda, A., Sabbah, H., Ababou-Girard, S., Solal, F. \& Godet, C. (2008). Appl. Surf. Sci. 254, 4980-4991. 